\title{
Revitalização de centros urbanos no Brasil: uma análise comparativa das experiências de Vitória, Fortaleza e São Luís
}

\begin{abstract}
The study of urban revitalization processes has taken pride of place in the studies of contemporary urban dynamics, given their frequency and broad scope. In the last few decades, they have stood out, among a variety of revitalization processes, for their ability to incorporate "culture" as a differentiating content. In this article, I evaluate the part the heritage has played in the latest attempts at revitalizing the historical areas of Vitoria (ES), Fortaleza (CE) and São Luis (MA), placing special emphasis on the role of the public power to enforce successful revitalization policies. In my opinion, the revitalization processes included in this paper point to innovative articulations among the players involved in them, once they comprise urban historical complexes with items of different values and are subject to local governments more or less committed to the revitalization of urban centers.
\end{abstract}

Key-words: Urban revitalization, cultural heritage, gentrification.

\section{Resumo}

O estudo dos processos de revitalização urbana tem ocupado um importante lugar na compreensão da dinâmica urbana contemporânea dada a frequiência e a abrangência que eles têm conhecido. Nas últimas décadas, estes processos têm se caracterizado por incorporarem a "cultura" como conteúdo diferenciador das várias experiências de revitalização. Neste artigo, avalio o lugar do patrimônio cultural nas experiências recentes de revitalização dos centros de Vitória (ES), de Fortaleza (CE) e de São Luís (MA), enfocando sobretudo o papel do poder público para obter êxito na implantação das políticas de revitalização. Considero que os processos de revitalização aqui enfocados apontam para articulaçóes inovadoras entre os atores envolvidos, na medida em que atingem conjuntos urbanos históricos diferentemente valorizados e passam por governos locais diferentemente comprometidos com os processos de revitalização dos centros urbanos.

Palavras-chave: revitalização urbana, patrimônio cultural, gentrification. 


\section{Introdução}

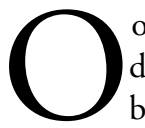
objetivo do trabalho é estudar os processos de revitalização urbana nas cidades brasileiras de Vitória (ES), Fortaleza (CE) e São Luís (MA), observando o lugar da cultura na justificação e na busca de legitimidade para tais processos, bem como as apropriaçōes de tais processos feitas pelos segmentos neles envolvidos ou por eles atingidos. As propostas de revitalização têm ocupado um importante lugar para a compreensão da dinâmica urbana contemporânea dada a frequiência e a abrangência que elas têm conhecido. Nas últimas décadas, estes processos têm se caracterizado por incorporarem a "cultura" como conteúdo diferenciador das várias experiências de revitalização. Neste sentido, o patrimônio histórico, as tradiçōes locais, a cultura popular e outros elementos têm se transformado em mercadoria altamente valorizada no mundo contemporâneo.

Uma ambigüidade latente nos processos de revitalização situa-se na tensão entre o local e o global. No cenário altamente competitivo da atual fase da economia de mercado, as cidades precisam se destacar através de um "diferencial" (a expressão tão cara aos defensores do marketing, inclusive o das cidades). A valorização da tradição e da cultura local tem sido um dos mais explorados. Mas, uma vez que o modelo difundido no mundo é o mesmo (os centros precisam se revitalizar para tornar as cidades competitivas), o que se observa em muitos casos é o comprometimento da diferenciação que existia em cada sítio, seja no aspecto cultural e dos usos e costumes locais, seja no plano urbanístico e arquitetônico.

Em geral os lugares, objetos dos processos de revitalização, eram, tempos atrás, possuidores de centralidade nas suas respectivas cidades. Em decorrências das diversas mudanças no planejamento, nas políticas urbanas e nos interesses do capital imobiliário, esses centros tradicionais foram perdendo a característica de centralidade para outras áreas, resultando em degradação desses espaços. Trata-se,

\footnotetext{
* Pontifícia Universidade Católica de Minas Gerais (Brasil). E-mail: tbotelho@pucminas.br.

"* Recibido el 6 de septiembre de 2004, aprobado el 1 de noviembre de 2004.
}

portanto, de uma experiência que está em pleno processo de avaliação e um fator que não deve deixar de ser pontuado é que na maioria dos casos, esses lugares, antes da revitalização, encontravam-se em uma situação de profundo comprometimento físico e social: lugares pouco povoados ou subutilizados, construções em situação de risco etc. Não resta muita dúvida sobre o fato da revitalização ter introduzido melhorias físicas ao lugar; o que está em avaliação e discussão é o caráter dos diferentes processos de revitalização.

Por outro lado, é necessário verificar como as intervençôes brasileiras se situam frente aos principais dilemas dos processos de revitalização já apontados pela literatura: como recuperar sem elitizar e sem expulsar os habitantes na época da intervenção? Se essa for a marca, estaríamos repetindo, um século depois, a experiência e os efeitos perversos das reformas urbanas do final do século XIX e início do XX? O uso dos espaços públicos deverá ser marcado pela contemplação e pelo consumo? As intervençôes, tal como têm sido realizadas, destinam-se às classes médias e altas ou podem vir a incorporar outros grupos? Dito de outra forma, a revitalização tornou-se sinônimo de gentrificação ou pode ser pensada também como forma de inclusão social, promoção da cidadania e reforço das identidades? Até que ponto as intervenções são ou não excludentes? Que grupos inclui e que grupos exclui?

Embora as experiências de revitalização estejam se disseminando pelo Brasil, até o momento as principais análises concentram-se nos casos mais visíveis ocorridos em grandes metrópoles. Salvador e Recife são consideradas as principais "vitrines" brasileiras, ao lado do Rio de Janeiro e de São Paulo. A proposta desse trabalho é apresentar outros casos de intervenção nas regióes centrais de capitais estaduais brasileiras, observando similitudes e evidenciando as diferenças. Foram escolhidas três capitais de estados brasileiros que estão vivendo processos de revitalização mas que foram ainda pouco estudadas: Vitória, Fortaleza e São Luís. Mesmo que não sejam os casos mais importantes de revitalização no Brasil, eles são bastante significativos e exemplares porque apontam para novas articulaçóes entre os atores envolvidos, além de terem sido conduzidos por diferentes instâncias do poder público. 
Os processo de revitalização aqui enfocados apontam para articulaçōes específicas entre os atores envolvidos (nível de poder público, investidores privados, agência de fomento e/ou patrocinadores) na medida em que apresentam conjuntos urbanos históricos diferentemente valorizados pelas agências estatais de proteção ao patrimônio cultural (alta valorização em São Luís, média valorização em Vitória e baixa valorização em Fortaleza) e passam por governos locais diferentemente comprometidos com os processos de revitalização dos centros urbanos (alto comprometimento em Vitória, médio em São Luís e baixo em Fortaleza). Nestes diferentes cenários, buscou-se perceber como a população apropria-se do "novo" espaço revitalizado e incorpora novos significados e usos. É importante ver como os habitantes e os freqüentadores desses lugares são excluídos, incluídos ou se fazem incluir a partir do seu cotidiano aí construído.

No desenvolvimento do trabalho, apresento inicialmente algumas das principais vertentes com que as ciências sociais têm analisado os casos de revitalização de centros históricos no mundo ocidental, situando a perspectiva pela qual se pretende aproximar dos casos em análise. Em seguida, apresento cada um dos casos, procurando enfatizar os aspectos que apontei acima. Ao final de cada caso, procuro ir articulando um quadro comparativo para tecer algumas consideraçôes sobre os rumos e os impasses desses projetos de revitalização. Como conclusão, reapresento rapidamente as linhas de força dos conjuntos analisados.

\section{Centralidade e revitalização nas grandes cidades do ocidente contemporâneo}

Os relatos sobre as experiências vividas pelas grandes cidades norte-americanas ao longo do século XX são bastante uniformes. Eles descrevem o esvaziamento sofrido por suas regiōes centrais em função do processo de suburbanização, agravado pelas grandes intervençôes urbanísticas que deterioraram ainda mais esses espaços urbanos. Em decorrências das diversas mudanças no planejamento, nas políticas urbanas e nos interesses do capital imobiliário, os centros tradicionais foram perdendo sua característica de centralidade para outras áreas ${ }^{1}$. A partir da década de 1960, autores como Jacobs (2001) se voltavam contra os modelos urbanísticos que teriam provocado tal esvaziamento e pregavam uma recuperação dos usos da rua e dos espaços públicos das grandes cidades.

Ainda nos anos 1960, alguns autores apontavam para novas transformações que vinham sendo observadas nos centros das grandes cidades norte-americanas e em algumas metrópoles européias. Os distritos "históricos" começavam a ser lentamente reocupados por alguns setores mais abastados das classes médias. Eles retornavam ao centro em busca das vantagens advindas das proximidades oferecidas pelos centros. Moradia, trabalho, lazer e consumo estavam disponíveis nos quarteirōes vizinhos para aqueles que se dispusessem a morar no centro da cidade. Associava-se a isso o valor que se começava a agregar aos imóveis mais antigos, muitos deles considerados de interesse para preservação histórica. $\mathrm{O}$ retorno desses pioneiros urbanos (para usar a expressão de Smith, 1996) se dava concomitantemente à chegada de novos usos que agregavam ainda mais "valores culturais" às áreas centrais. Galerias de arte, ateliês de artistas novos ou em ascensão, restaurantes e cafés refinados iam surgindo, formando seu público e reafirmando a conquista do território central.

Em 1963, esse processo recebeu o nome de gentrification, dado por Ruth Glass em sua obra Introduction to London: aspects of change (ver BidouZachariasen, 2003). Em seguida, o termo foi utilizado na descrição de diversos outros processos semelhantes de requalificação dos centros históricos de grandes cidades. Para Smith (1996 e 2003), o processo inicialmente tinha algo de espontâneo e conduzido pelo mercado imobiliário. Ao longo dos anos 1990, tornou-se uma política urbana, uma estratégia articulada e global que representa uma conquista classista da cidade.

Para Zukin (1991, 1995 e 2000), tais espaços integram as chamadas paisagens urbanas pós-modernas. Ao lado dos cenários formados por "torres altas que voltam suas costas para a rua" (2000, p.

${ }^{1}$ Pode-se ver alguns desses relatos em Bright (2000). 
82), surgem também a restauração e a renovação de antigos lugares. Esse processo ocorre no que ela denomina de cidades antigas (cujos centros se constituíram ao longo do século XIX e da primeira metade do século XX), articulado à recentralização do investimento global nas grandes cidades e à acumulação de capital nas economias dominadas pelo setor de serviços.

Nos casos de revitalização urbana, deve-se destacar como a produção de novos cenários, ou novas paisagens, apresenta-se enquanto uma articulação específica entre a recuperação das edificações nomeadas como históricas e as novas construçōes de caráter monumental. Está-se diante da construção do discurso da cidade como imagem. Segundo Huyssen (2000, p. 100), "a imagem da cidade propriamente dita torna-se central para seu sucesso em um mundo globalmente competitivo".

Essas relações conduzem-nos a outras perspectivas sobre tais processos observados nas cidades ocidentais contemporâneas. Desde os anos 1980, surgem de forma cada vez mais disseminada e dominante os discursos sobre o city marketing, a cidade como mercadoria a ser oferecida no mercado global. A necessidade de atrair fluxos de capital que, em tese, garantiriam a sobrevivência e o crescimento da cidade faz com que muitas delas adquiram o "pacote" de tecnologias gerenciais do urbano. Tal pacote inclui o planejamento estratégico, a criação de consensos entre os cidadãos, o "patriotismo de cidades" etc. ${ }^{2}$

Dentro do mercado de cidades, torna-se necessário garantir um diferencial entre elas. Em função disso, há uma valorização do que é entendido como a "cultura local". As expressões artísticas, as manifestações populares e o patrimônio histórico passam a ser enfatizados. Os discursos em torno da identidade local são constituídos também como um apelo à preservação do patrimônio histórico edificado, que é muitas vezes recuperado como cenário local a ser desfrutado pelos consumidores de lugares (Arantes, 2000). É sintomático que muitas cidades européias que não sofreram os processos de

${ }^{2}$ Como testemunha desse consenso criado em torno de procedimentos a serem adotados na gestão das cidades, ver BID (1998). Para uma crítica ao planejamento estratégico e ao city marketing, ver Vainer (2000a e 2000b) e Sánchez (2001). esvaziamento profundo do seu centro (como o observado nas cidades norte-americanas) estejam vivenciando os processos de revitalização enquanto a produção de espaços de consumo de luxo. Em diversos casos, não se observa um processo de gentrificação residencial, mas de consumo e de freqüência (Bidou-Zachariasen, 2003).

No caso da América Latina, os processos de revitalização têm acompanhado as tendências apontadas, embora com nuances específicas. A ênfase discursiva na valorização do específico e do local fazse presente em todas as experiências articuladas de revitalização de centros urbanos. $\mathrm{O}$ apelo ao patrimônio histórico edificado presente nas áreas centrais das principais metrópoles latino-americanas dá ainda mais força a esse discurso. Entretanto, a inserção subordinada da região aos fluxos internacionais de capitais e serviços imprime-lhe cores próprias vis-a-vis as cidades das economias centrais. Uma primeira observação é quanto a um menor dinamismo nos processos de revitalização. Em segundo lugar, a revitalização provoca uma modificação dos usos, mas raramente muda o padrão residencial das áreas afetadas. Mas o principal elemento diferenciador diz respeito ao papel do poder público como condutor dos processos de revitalização.

Analisando o caso de diversas cidades mexicanas, Melè (1998, p. 11) enfatiza a "visibilidade da ação pública” frente ao desinteresse relativo de certas formas de capital imobiliário frente a essas intervençōes nos centros urbanos. Hiernaux (2003) mostra que no caso da Cidade do México, a sua elevação pela Unesco à condição de "patrimônio da humanidade", em 1984, levou o poder público local a elaborar estratégias de recuperação do seu centro histórico.

No Brasil, os principais casos de revitalização de centros históricos de grandes cidades também são marcados pela presença do poder público, em especial no financiamento das intervenções. Em Salvador, o projeto de revitalização do Pelourinho baseouse em uma verdadeira reconstrução do cenário urbano que se queria recuperar. Implicou em desapropriaçõos e em obras civis de envergadura que foram financiadas por recursos públicos nacionais e internacionais. A expectativa de que a recuperação da área pudesse gerar uma valorização de seus imóveis e com isso permitir o retorno do investimento públi- 
co, ao que parece, não se confirmou (Azevedo, 1994; Gomes, 1995). Em Recife, embora se enfatize a parceria entre poder público e investidores privados (Zanchetti e Lacerda, 1999), foi o primeiro que de fato conduziu todo o processo (Leite, 2002 e 2003).

No Rio de Janeiro, também é o poder público o condutor da revitalização do centro histórico da cidade. Nesse caso, inclui-se, ainda, a luta do poder público municipal pela vinda de uma franquia internacional de museus (o Guggenheim Museum) que seria tomada como a âncora da recuperação de sua zona portuária. $\mathrm{O}$ debate que se travou ao longo do ano de 2003 centrou-se nos impactos que tal construção provocaria na área escolhida para abrigala e no financiamento da obra, que até o momento só contava com recursos públicos ${ }^{3}$.

O caso de São Paulo diferencia-se em parte dos demais porque contou desde o início com uma associação de proprietários da área como motor principal da revitalização. A Associação Viva o Centro, criada em 1991, surgiu como uma reação de empresários ali estabelecidos ao processo de esvaziamento e degradação do Centro Velho (Frúgoli, 2000). Embora tenham levado adiante diversas iniciativas de requalificação e revalorização do centro, deve-se reconhecer que os principais equipamentos recuperados ou implantados o foram a partir de investimentos do poder público, direta ou indiretamente (no último caso, graças a incentivos fiscais). É o que ocorreu com a reforma da Pinacoteca do Estado, a implantação da Sala São Paulo e outros.

Frente a esse cenário, éinteressante observar outras experiências brasileiras de revitalização. Nos casos que irei apresentar adiante, procurarei responder, ou ao menos problematizar, as questôes colocadas inicialmente, adotando, todavia, uma perspectiva que pretende ir além das linhas de força observadas na literatura revista acima. Os casos analisados podem, e devem, ser vistos a partir da moldura construída acima. Os processos de revitalização parecem respon-

${ }^{3}$ Ver a esse respeito, por exemplo, a cobertura do jornal Folha de S. Paulo nas edições de 27/06/2003 (p. E12), 29/ 05/2003 (p. C3 e C7), 21/05/2003 (p. C7), 05/05/ 2003 (p. C4), 03/05/2003 (p. E7), 01/05/2003 (p. C3), 26/04/2003 (p. E2), 14/04/2003 (p. C3) e 19/03/ 2003 (p. E3), dentre outras. der às demandas colocadas na ordem do dia das cidades pelas novas configuraçôes do mundo globalizado. Essas demandas adequam-se aos constrangimentos típicos das cidades latino-americanas. Enquanto tal, implicam em arranjos peculiares dos diversos atores sociais envolvidos com o espaço urbano em foco. Mas, além disso, estaremos observando cidades brasileiras que se colocam em posição subordinada dentro do próprio espaço nacional. Elas não apresentam uma inserção internacional (ainda que secundária) como São Paulo e Rio de Janeiro, nem são metrópoles regionais importantes (à exceção parcial de Fortaleza), como Salvador e Recife. Essa dupla subordinação cria constrangimentos que marcam profundamente tais experiências e que por isso mesmo explicitam contradições encobertas nos casos até então estudados.

Pretendo evidenciar o caráter peculiar dos diferentes processos de revitalização das áreas centrais das cidades escolhidas. Por revitalização estou entendendo as políticas públicas de investimento em áreas delimitadas dos centros urbanos com a finalidade de reverter processos de degradação física e de "guetização" de determinados espaços. O diagnóstico da perda da vitalidade surgiu em algum momento do processo de formulação das políticas urbanas. Para os casos analisados, tal diagnóstico resultou em açóes públicas que desencadearam os processos sociais em análise. Deve-se lembrar que foi isso que tornou os casos elegíveis para o estudo. Desse modo, não pretendo questionar se as áreas escolhidas para intervenção nessas cidades viviam ou não tais processos de degradação, mas apenas evidenciar que foi uma constatação de tal ordem que detonou os processos de revitalização em análise.

Uma das questôes a ser colocada ao longo da análise dos casos refere-se à ocorrência de processos de gentrification nas áreas que sofreram a revitalização. Assim, adoto uma definição do termo mais específica e mais apropriada aos casos brasileiros. Seguindo Leite (2002, p. 118), gentrification será entendida enquanto "intervenções urbanas como empreendimentos que elegem certos espaços da cidade considerados centralidades e os transformam em áreas de investimentos públicos e privados, cujas mudanças nos significados de uma localidade histórica faz do patrimônio um segmento de mercado". 


\section{O Caso de Vitória}

\subsection{Evolução urbana}

Vitória, município de 292 mil habitantes, é a capital do estado do Espírito Santo e o centro comercial da região metropolitana que compreende, além da capital, os municípios de Vila Velha, Cariacica, Serra, Viana e Guarapari, abrigando, ao todo, 1,42 milhão de pessoas (dados do Censo de 2000). A economia da região está atrelada a grandes empresas como a Companhia Siderúrgica de Tubarão, Aracruz Celulose, Samarco, Companhia Vale do Rio Doce e Portobrás. Os portos de Vitória e de Tubarão são ícones da indústria exportadora competitiva, que dá identidade à região, tanto no plano imagético, quanto no cultural (Fonseca, 2003).

A região foi ocupada desde a década de 1550, e a vila instalou-se no espaço hoje correspondente ao centro tradicional porque, além de propício para a construção de ancoradouros, o local era resguardado da costa, de difícil acesso e íngreme, o que permitia a visão antecipada de possíveis invasores. Baseada na economia do açúcar, a região não apresentou maiores dinamismos até o século XIX. Com o estabelecimento do café na província, o porto ganhou certo destaque como escoadouro da produção regional para o Rio de Janeiro. Outro elemento transformador importante foi a introdução de imigrantes europeus a partir da segunda metade do século XIX, que mudou a face de muitas regiōes da província, inclusive da capital. Durante o período republicano, o estado do Espírito Santo permaneceu em uma posição subordinada face a outras regiōes do Brasil. A partir da década de 1960, a região de Vitória ganhou importância como porto exportador do minério de ferro vindo de Minas Gerais através da Estrada de Ferro Vitória a Minas.

As políticas públicas do Estado do Espírito Santo priorizavam o centro como destino de investimentos até os anos 1960. A partir de então, o crescimento populacional acelerado, conjugado à percepção de que a região central apresentava uma saturação funcional e não correspondia à demanda de expansão, fizeram com que o poder municipal abandonasse o centro e expandisse a malha urbana. A ação planificada do poder público e a especulação imobiliária promoveram a descentralização e a polinucleação da cidade, reduzindo o centro original a um "corredor de tráfego", com importância deliberadamente diminuída. A população de maior poder aquisitivo, não encontrando mais funcionalidade ou segurança na região, transferiu-se de lá para bairros no norte da Ilha, tais como Praia do Canto, Jardim da Penha e Mata da Praia (Botechia, 2001; Campos Jr., 2002).

A degradação do centro transpareceu principalmente através do abandono e desvalorização de imóveis, da retirada da classe média e do poder público e da popularização do comércio. Também é possível constatar uma deterioração da paisagem urbana, a descaracterização de conjuntos históricos e um certo esvaziamento demográfico. A área não chegou, no entanto, a um estágio de deterioração tão avançado como o de outras capitais brasileiras que diagnosticaram a necessidade de intervenções para revitalizar o centro, tais como Recife e Salvador.

Nos anos 1980, a região voltou a receber investimentos municipais, que vieram na esteira de transformações na concepção de planejamento urbano nacional. O centro, por sua vez, voltou a ter a atenção do poder público, em função de um discurso que traz elementos como a "qualidade de vida", a "valorização do patrimônio histórico" e a "participação popular” para justificar as intervenções urbanas. Influenciadas pela perspectiva empreendedorista do city marketing americano e do planejamento estratégico catalão, as políticas públicas do município passaram a orientar-se por um planejamento de resultados, que idealiza a inserção da cidade em um contexto de globalização, a partir de sua imagem.

\subsection{Planejamento estratégico e revitalização urbana}

Em Vitória, o tema da revitalização do centro teria surgido em 1986/1987, quando "um projeto acadêmico de Graduação do Curso de Arquitetura e Urbanismo da Universidade Federal do Espírito Santo (UFES) levantou as primeiras discussões acerca da necessidade de uma política efetiva de revitalização da área central, que já apresentava, desde o final da década de 1970, sinais visíveis de esvaziamento, através da transferência dos investimentos para a região norte da cidade, contribuindo para o abandono e a paulatina degradação dos espaços do centro" (Prefeitura Municipal de Vitória, s/d). 
Durante a administração Paulo Hartung (19931996), foi elaborado um projeto de plano estratégico para a cidade, a cargo da Companhia de Desenvolvimento de Vitória (CDV). O trabalho foi concluído apenas no início da gestão seguinte, do prefeito Luiz Paulo Vellozo Lucas (1997-2000). Foi então publicado o documento Vitória do Futuro: Plano Estratégico da Cidade, 1996-2010, que incorporou de forma bastante significativa o tema da revitalização do centro da cidade (Prefeitura Municipal de Vitória, 1996) ${ }^{4}$.

Em seu diagnóstico (“Como está Vitória”), o Centro foi apresentado como "centro vital da cidade de Vitória e também como o núcleo central da região que englobava os demais municípios vizinhos" (Prefeitura Municipal de Vitória, 1996, p. 38). À época, no entanto, constatava-se a ausência de "funcionalidade, segurança e beleza a quantos fazem dele o seu habitat, seja por opção ou necessidade", com "uma brutal redução no ritmo dos investimentos em construção de novas edificações e na modernização e recuperação das já existentes" (Prefeitura Municipal de Vitória, 1996, p. 38-9). Daí a desvalorização da área da cidade, bem como a sua transformação em local progressivamente degradado e violento. Registrava-se, contudo, a presença de "prédios de valor histórico de grande significado para a memória social e histórica de Vitória e do Estado" (Prefeitura Municipal de Vitória, 1996, p. 39). Para estes, a Prefeitura já havia tomado iniciativas de proteção, dentre os quais se destacava o Projeto de Revitalização do Centro de Vitória.

Dentro do figurino recomendado pelo planejamento estratégico, traçaram-se cenários futuros de Vitória, tanto numa perspectiva negativa ("O Caminhar do Caranguejo") quanto otimista ("O Salto do Marlim Azul”). Nesse último caso, seriam criadas "condições para ações que preservem e melhorem a qualidade de vida na cidade, tornando-a cada vez mais competitiva e diferenciando-a de outras metrópoles" (Prefeitura Municipal de Vitória, 1996, p. 58). O centro da cidade seria valorizada, pois "a manutenção das áreas preservadas e o tratamento dado ao patrimônio histórico, cultural e natural e à paisagem urbana possibilitarão o surgimento de

\footnotetext{
${ }^{4}$ Sobre o Plano Estratégico de Vitória e sua influência na construção do imaginário da cidade, ver Bank (1998).
}

novos vínculos dos moradores com a cidade" (Prefeitura Municipal de Vitória, 1996, p. 59). O patrimônio histórico, portanto, surge como elemento central na redefinição dos usos do centro, já que ele forneceria o diferencial que garantiria a posição única da região na nova configuração assumida pela cidade. De área demonizada, o centro passaria à condição de garantidor da identidade cultural de Vitória.

Para conseguir alcançar o cenário positivo descrito no documento, seriam necessários diversos esforços do município. Dentre os temas e projetos apontados, era significativa a presença do tema da revitalização, articulado com o do patrimônio histórico, percorrendo diversos momentos do Plano Estratégido da Cidade de Vitória. Neste sentido, pode-se falar de um razoável consenso alcançado por estes dois aspectos dentro das discussões sobre a gestão da cidade .

No início de 2002, o Plano Plurianual 20022005 apresentava como uma de suas Orientações Estratégicas "preservar e restaurar os patrimônios histórico, cultural e ambiental, dinamizando e democratizando seu aproveitamento pela sociedade" (http://www.vitoria.es.gov.br/secretarias/estrategica/ ppa5.doc). Articulada a esta orientação, a Revitalização do Centro aparecia como programa finalístico, cujo objetivo era "revalorizar o Centro de Vitória, em parceria com a sociedade, nos aspectos sócio-econômico, histórico-cultural, ambiental e urbano, potencializando suas especificidades" (http:// www.vitoria.es.gov.br/secretarias/estrategica/ leis.htm).

Interessa notar que tanto no Plano Estratégico da Cidade de Vitória quanto no Plano Plurianual 2002-2005, o tema da revitalização do centro aparece fortemente, embora não exclusivamente, associado ao tema do patrimônio cultural. No caso do Plano Estratégico, esta dimensão da vida da cidade deveria ser contemplada porque seria o elemento que diferenciaria a cidade dentro do cenário globalizado

${ }^{5}$ No início de 2002, o site do Projeto Vitória do Futuro falava da elaboração da versão 2002 do Plano Estratégico da Cidade 2002-2015 "“Saiba mais sobre o Vitória do Futuro versão 2002", http://www.vitoriadofuturo.org.br). Nesta nova versão, a idéia seria incorporar a Agenda 21, assumindo a dimensão do desenvolvimento sustentável. 
competitivo. Além disso, ele também seria um dos elementos garantidores da sustentabilidade do desenvolvimento que se queria para a cidade ${ }^{6}$.

No ano anterior (2001), a Prefeitura Municipal de Vitória teve seu Programa de Revitalização do Centro classificado em $34^{\circ}$ lugar dentro do Programa Monumenta BID, destinado à aplicação de recursos desta agência multilateral na recuperação de sítios históricos urbanos no Brasil ${ }^{7}$. Embora não tenha recebido os recursos, pois apenas 20 cidades brasileiras foram contempladas pelo programa, destaco o esforço de sistematização requerido pela elaboração do projeto. Os técnicos da equipe envolvida com a elaboração da proposta deixam transparecer este esforço, que só foi possível graças à articulação entre as diversas ações que o projeto de revitalização do centro já vinha promovendo.

Outra ação de relevo foi a recuperação de edifícios de valor histórico no centro. Através da Escola $\mathrm{Mu}$ nicipal Profissionalizante de Arte e Ofício (EMPAO) e com o patrocínio da Companhia Siderúrgica de Tubarão, já foram recuperadas algumas construções. Em junho de 2003, segundo a diretora Karin Maia, duas obras (Atacadão dos Tecidos e Supermercado São José) estavam em fase de conclusão e outras quatro estavam na agenda de serviços ${ }^{8}$.

Se o patrimônio histórico edificado ocupa este lugar tão importante nos projetos de revitalização do centro de Vitória, resta perguntar o que se deseja preservar. A primeira aproximação ao tema pode vir dos imóveis tombados no centro da cidade. São 5 imóveis com tombamento federal, através do IPHAN: a Capela de Santa Luzia (século XVI), a

${ }^{6}$ A associação entre patrimônio cultural e sustentabilidade é um tema ainda pouco explorado. Para uma primeira aproximação, ver Acselrad (2001).

O documento de Vitória previa recursos totais da ordem de 26,8 milhões de reais, destinados à: recuperação de 7 imóveis com destinação especial/pública; recuperação de fachadas dos imóveis de interesse de preservação da principal via comercial da Cidade (Avenida Jerônimo Monteiro) -Projeto "Descobrindo a Cidade"; projetos urbanísticos/ paisagísticos (10 projetos); e ações/campanhas de conscientização (Prefeitura Municipal de Vitória, s/d).

${ }^{8}$ Karin Maia, entrevista em 17/06/2003. Um balanço de todas as ações desenvolvidas no centro pode ser encontrado no relatório anual de atividades da Administração Regional do Centro (Prefeitura Municipal de Vitória, 2003).
Igreja do Rosário (1765), a Igreja de São Gonçalo (1707-1766) e dois sobrados coloniais da Rua José Marcelino. Além deles, existiam 14 tombamentos estaduais e 9 imóveis tombados pelo município até o ano de $2000^{9}$. No nível municipal, existe ainda a categoria do imóvel identificado, que não recebe a proteção do tombamento mas tem restrições quanto a reformas e demolições, além de poder receber os incentivos fiscais definidos pela prefeitura (sobretudo isenção de IPTU $)^{10}$.

\subsection{A área revitalizada: situação atual}

Aquele que transitasse pelo centro de Vitória em meados de 2003 poderia perceber alguns dos resultados dos esforços de revitalização. Uma série de edificaçōes ao longo da Avenida Jerônimo Monteiro, a mais movimentada da região, encontrava-se com as fachadas desobstruídas e recuperadas. Nesse conjunto incluíam-se tanto edificações públicas (a antiga Faculdade de Filosofia, o Museu de Arte do Espírito Santo) quanto imóveis comerciais privados. A Praça Costa Pereira, localizada ao meio do percurso da Avenida, concentrava outras edificaçôes e equipamentos públicos recuperados. Ao final da Avenida, a encosta onde está o Palácio do Governo também apresentava uma paisagem renovada. As suas escadarias e algumas edificaçôes laterais haviam sido recentemente recuperadas e pintadas. Nesse ponto, a principal marca na paisagem é o porto. Situando-se no centro da cidade, ele desempenha um duplo papel. Por um lado é um fator a desqualificar a área, pela própria natureza de suas atividades e por criar uma barreira para a baía que até então se podia acompanhar. Por outro lado, apresenta um aspecto surpreendentemente agradável face a outras regiōes portuárias. Não se observavam os sinais ostensivos de abandono e de degradação comumente associados a esses espaços urbanos.

Nesse ponto, o transeunte é conduzido a uma inflexão na sua rota, devendo optar entre duas

\footnotetext{
${ }^{9}$ Não se tem notícia de tombamentos estaduais posteriores, mas devo ressaltar as dificuldades de acesso a essas informações junto ao órgão responsável.

${ }^{10}$ Informações obtidas com os técnicos Pedro Canal e Jaqueline Marquese, da Divisão de Revitalização de Áreas Urbanas da Secretaria Municipal de Desenvolvimento Urbano, entrevista em 29/06/2001.
} 
direçōes: ou segue em frente e dirige-se à Vila Rubim, ou segue à direita e entra na região do Parque Moscoso. Esse parque havia sido recentemente recuperado e reaberto ao público. Ocupa uma enorme quadra na parte posterior da colina onde se implantou a cidade alta. Em seu entorno, edifícios de apartamentos convivem com sobrados e casas que testemunham o perfil da ocupação inicial da área. $\mathrm{O}$ parque surgiu como elemento valorizador da área e era uma referência para os visitantes da cidade. Mais recentemente, havia se tornado um fator degradador, ocupado por pessoas que os habitantes do local qualificam de "prostitutas", "malandros" e "vadios". A recente recuperação pretendeu resgatar a imagem inicial do parque e produzir efeitos rejuvenescedores no entorno. Embora algumas casas vizinhas tenham de fato sido restauradas, muitas permanecem em estado precário.

Seguindo para a Vila Rubim, penetra-se em uma região de comércio popular que se estende até o Mercado. Esse era um antigo ponto de comercialização de bens para o consumo cotidiano da cidade. Surgiu em função de um atracadouro que permitia o desembarque dos produtos vindos do interior. $\mathrm{O}$ fim do canal e do atracadouro não esvaziaram a vocação comercial da área. Na década de 1970, foram construídos galpões para abrigar seus comerciantes. A partir de 1981, com a implantação da Ceasa em Cariacica, a região passou por um processo de decadência que culminou com seu incêndio em julho de 1994. Segundo o presidente da Associação dos Comerciantes do Mercado da Vila Rubim, Renato Freixo, depois de inúmeros conflitos entre o governo estadual, o governo municipal e a associação dos comerciantes, estabeleceu-se um plano de recuperação da área que incluiu a reconstrução do galpão incendiado (já concluída), a substituição dos demais (ainda pendente) e a redefinição das suas atividades com o objetivo de voltar-se para o turismo (entrevista em 16/06/2003).

A Associação dos Comerciantes do Mercado da Vila Rubim é uma das diversas associaçôes da região central da cidade. Muitas delas foram criadas por estímulos da própria prefeitura, que as utilizou como canal de comunicação com a população, sobretudo quando da elaboração do Plano Estratégico da cidade. Embora essas associações representem um papel interessante na organização das demandas dos moradores das áreas do centro, elas não deixam de ter um certo caráter para-oficial.

A grande articuladora e animadora dessas experiências no centro de Vitória é a Administradora Regional do Centro da Prefeitura Municipal de Vitória, Lilia Mello. Originalmente técnica do BNDES no Rio de Janeiro, ela retornou a Vitória no início da década de 1990 para trabalhar em projetos da prefeitura e desde 1997 é a administradora regional. Acompanhou o processo de elaboração do Plano Estratégico da Cidade, que defende como instrumento democrático e vital para a continuidade das ações da prefeitura. Segundo seu depoimento, projetos de revitalização do centro existem desde a década de 1980, mas apenas a partir de 1997 eles se tornaram mais articulados dentro do Plano Estratégico, abrangendo inclusive o entorno do centro (entrevista em 18/06/2003).

O cenário de progressivo sucesso que se vislumbra ao percorrer o centro de Vitória é substituído por outras sensações durante a noite. À medida que cessa o movimento provocado pelo comércio ou pelo trânsito das pessoas voltando para suas residências, $o$ centro esvazia-se, sobretudo ao longo da Avenida Jerônimo Monteiro. A ausência de moradores em muitas dessas áreas aqui descritas faz com que o cenário de intensa atividade durante o dia seja substituído pelo vazio noturno. Mesmo os hotéis situados na região encontram-se cada vez mais desocupados e sob ameaça de fechamento. Esse é reconhecidamente o calcanhar de Aquiles do processo de revitalização do centro. Para fazer frente ao problema, a recém-criada (2003) Secretaria Municipal de Habitação estava empenhada em implantar políticas de moradia no centro aprovadas pelo Conselho Municipal de Habitação. Assim, estava sendo elaborado o projeto Morar no Centro, em parceria com a Caixa Econômica Federal através do Programa de Arrendamento Familiar ${ }^{11}$. Segundo a Sub-Secretária Municipal de Habitação, Eliana Abaurre Ferrari, esse projeto inspirava-se em experiências já realizadas no Rio de Janeiro e em São Paulo. Voltava-se, sobretudo, para a readequação de prédios abandonados e sua transformação em moradias populares (entrevista em 17/06/2003).

11 Informações sobre o PAR podem ser obtidas em: https://webp.caixa.gov.br/urbanização/Publicacao/Texto/ programa/PAR.htm. 
O que deve ser ressaltado na experiência de Vitória é o fato do poder público local ser o grande condutor de todo o processo. Mais que isso, ele se posicionou em permanente confronto com o governo estadual, superado apenas após as eleições de 2002 em que venceu o candidato do mesmo partido do prefeito (PSDB). As especificidades do espaço físico do centro também imprimem marcas próprias à revitalização. Ele é pensado para abranger uma área bastante extensa, incluindo elementos que tradicionalmente não entram na agenda desses processos de revitalização; é o caso do Mercado da Vila Rubim, desprovido de interesse arquitetônico (embora de grande interesse cultural) e afastado do núcleo histórico da cidade. Finalmente, o local apresenta poucas edificações reconhecidas pelas agências patrimoniais públicas como de alto interesse histórico, concentrando sobretudo elementos significativos da trajetória local. Se pudermos falar em gentrification do centro de Vitória, ela ainda é uma possibilidade no cenário futuro, já que o estágio atual não comporta esse qualificativo. O empenho da Prefeitura Municipal de Vitória em implantar o Programa Morar no Centro, voltado para a população de baixa renda, parece sinalizar na direção contrária a isso ${ }^{12}$.

\section{O Caso de Fortaleza}

\subsection{Oprocesso de urbanização}

A cidade de Fortaleza, com 2,14 milhões de habitantes, é o centro de uma região metropolitana com 2,98 milhôes de moradores (dados do Censo de 2000). Além das atividades inerentes à sua posição de metrópole regional, a cidade se destaca como um pólo de atração turística. A presença de praias dotadas de belezas naturais em um raio de $200 \mathrm{Km}$ da capital e a escassez de chuvas na região a transformaram em um destino turístico importante nas últimas décadas. Tem atraído, também, turistas estrangeiros, favorecidos pela proximidade da Europa mas também pela imagem que se criou em torno do turismo sexual ${ }^{13}$.

${ }^{12}$ O programa foi lançado oficialmente em 27/11/ 2003. Ver maiores informações em: http:// www.vitoria.es.gov.br/secretarias/habitacao/noticias.htm.

${ }^{13}$ Sobre o turismo cearense em geral e o turismo sexual em particular, ver, respectivamente, Benevides (1998) e Benevides e Gondim (1998).
A tardia ocupação do Ceará deu-se mais por razões estratégicas que econômicas. A necessidade de ligar por terra a ocupação do litoral leste com os estabelecimentos portugueses no Maranhão e Pará fez com que se empreendesse, a partir do século XVII, a exploração e a ocupação mais efetiva do território cearense. A povoação inicial surgiu em 1649, mas foi elevada a vila apenas em 1726 . No interior, as fazendas de gado avançaram pelas enormes áreas aptas à pecuária extensiva, dentro dos marcos do processo de expansão dessa atividade nordestina. $\mathrm{O}$ Ceará recebeu o influxo tanto do avanço da pecuária pernambucana, que respondeu pela ocupação de áreas mais próximas ao litoral, quanto da pecuária baiana, que esteve presente na ocupação do seu oeste e sudoeste. No século XIX, uniu-se ao gado o algodão, assumindo enorme importância nas regiōes interioranas. O seu caráter exportador fez com que o algodão consolidasse a importância de Fortaleza na economia regional, reafirmando seu poder político (Souza, 1989).

Ao longo dos séculos XIX e XX, assistiu-se à concentração de atividades diversificadas em torno da capital. As suas funções políticas reforçavam o desenvolvimento econômico, e a centralização de políticas de amparo aos atingidos pelas secas sucessivas do interior do Estado provocou um contínuo crescimento da sua população. Como o local não oferecia condições naturais para o estabelecimento de um porto, essas atividades sempre dependeram de vultosos investimentos (para os padrões locais) na construção de atracadouros artificiais. A área central da cidade recebeu o primeiro deles, em princípios do século XX. Em torno dessa área, foram sendo construídas edificações para abrigar armazéns e escritórios comerciais. Com a mudança do porto para a região do Mucuripe, nas décadas de 1940 e 1950, a área sofreu um progressivo esvaziamento, sendo seus imóveis ocupados como depósitos (os galpões) e como local de trabalho e moradia de prostitutas e de segmentos de baixa renda.

A partir da década de 1970, a cidade sofreu uma forte expansão em direção oeste, avançando sobre a chamada Praia de Iracema e daí em frente. Os novos bairros que passaram a abrigar a classe média mais abastada afastam-se do centro. Com o crescimento do turismo, os novos hotéis e restaurantes são construídos ao longo da avenida que margeia 
a praia de Iracema e seus segmentos. No mesmo período, o governo estadual transferiu a maior parte dos serviços públicos para o Centro Administrativo do Cambeba, situado em área distante do centro. Esse processo reforçou ainda mais o esvaziamento da zona central, provocando o que se poderia classificar como uma perda de centralidade ${ }^{14}$.

\subsection{A revitalização urbana e o Centro Dragão do Mar de Arte e Cultura}

Em Fortaleza, a principal experiência de revitalização da área central da cidade deu-se no entorno do Centro Dragão do Mar de Arte e Cultu$\mathrm{ra}^{15}$. Embora tenham acontecido experiências pontuais de revitalização de outras partes da cidade (Praça do Ferreira, Praça José de Alencar), foi a área do Centro Dragão do Mar de Arte e Cultura que assistiu ao maior investimento e ao maior envolvimento de bens imóveis considerados de valor histórico. Inicialmente, a idéia era construir um centro cultural, que abrigaria uma série de equipamentos (museu, cinema, planetário e outros), associado à Biblioteca Pública do Estado do Ceará. Tratava-se, portanto, de um projeto capitaneado pelo poder público estadual.

$\mathrm{O}$ arquiteto Fausto Nilo, um dos responsáveis pelo projeto do Centro Dragão do Mar de Arte e $\mathrm{Cultura}^{16}$, oferece uma primeira perspectiva desse processo. Segundo ele, o termo de referência inicialmente divulgado pelo governo estadual não falava da necessidade de incorporar o casario da área ao projeto do Centro Cultural. Dizia apenas de uma edificação que pudesse influir de maneira positiva na vizinhança. Da sua equipe teria surgido a idéia de incorporar as edificaçōes existentes: "Como não temos memória, é bacana que se preserve coisas para formar um percento de todos os tempos" (entrevista em 27/ 01/2003).

\footnotetext{
${ }^{14}$ Sobre as transformações da cidade de Fortaleza e sua articulação com os processos de revitalização do centro e da região do Centro Dragão do Mar de Arte e Cultura, ver Gondim (2001a, 2001b e 2003).

${ }^{15}$ Para uma problematização das concepções de preservação ligadas aos processos de revitalização em Fortaleza, ver Barreira (2001a, 2001b e 2003).

${ }^{16}$ A autoria do projeto é compartilhada com Delberg Ponce de Leon.
}

O Centro Dragão do Mar de Arte e Cultura foi pensado como uma forma de criar um circuito que ligasse a área comercial da Avenida Monsenhor Tabosa (artéria com intenso comércio voltado para os turistas) e a área central da cidade. A intenção seria recuperar essa região da cidade ao usufruto dos cidadãos que teriam dela se afastado com o crescimento urbano. Por traz das intenções do arquiteto, sobressai a necessidade de recuperar dimensões perdidas do convívio na cidade contemporânea.

Aproveitando-se da envergadura assumida pelo projeto, os técnicos do Departamento de Patrimônio da Secretaria de Cultura e Desporto do Estado do Ceará propuseram a inclusão de uma área de interesse de preservação dentro da intervenção a ser feita no centro da cidade. Inicialmente, pensou-se em incluir o polígono formado pelas avenidas do Imperador, Dom Manoel e Duque de Caxias e o litoral; seriam "os três grandes boulevares que definem o centro da cidade, uma área muito grande", segundo Frederico Bastos, técnico do Departamento de Patrimônio $^{17}$. Tendo buscado assessoria da Fundação Roberto Marinho, decidiu-se por restringir o trabalho à área conhecida como Praia de Iracema, ou Prainha $^{18}$. Nesta nova definição, seriam atingidas 50 edificações, que puderam ser tratadas de forma bastante particularizada. Estas edificaçôes distribuíam-se em 2 quarteirōes inteiramente atingidos e 8 quarteirões parcialmente atingidos. $\mathrm{O}$ projeto recebeu o nome de "Cores de Fortaleza", dentro do projeto maior da Fundação Roberto Marinho, intitulado "Cores da Cidade", tendo sido patrocinado pelas Tintas Ypiranga. Seguindo orientaçōes da Fundação, foi criado um escritório

${ }^{17}$ Esta e outras informaçōes sobre o processo de revitalização do centro de Fortaleza foram obtidas com Mardônio Guedes e Frederico Bastos, do Departamento de Patrimônio da Secretaria de Cultura e Desporto do Estado do Ceará, entrevistas em janeiro de 2002.

${ }^{18}$ É interessante notar que a denominação da área sofre uma certa adaptação para fugir dos estigmas acumulados no período em que esteve abandonada. Segundo Frederico Bastos: "A Praia de Iracema que nós conhecemos em Fortaleza é a praia que está no Estoril. O Dragão do Mar está no Bairro da Prainha, Outeiro da Prainha. Só que ninguém fala mais Outeiro da Prainha, que era meio pejorativo, que era uma área que só tinha cabarés, prostituição, armazéns, era uma área degradada” (entrevistas em janeiro de 2002). 
"que pudesse dar toda uma fundamentação econômica e social para a área [...]. Não de gestão, [mas] de viabilização econômica de toda aquela área. Então, seria feito um estudo, um levantamento estatístico do potencial que aquela área teria" (Frederico Bastos, entrevistas em janeiro de 2002).

O trabalho realizado foi, basicamente, de recuperação de fachadas. Elas tiveram seus detalhes originais restaurados e receberam nova pintura. Com a inauguração simultânea do Centro Dragão do Mar de Arte e Cultura, a área foi rapidamente ocupada por uma série de atividades econômicas, ditadas pelo perfil do público que passou a dirigir-se para o local: bares, boates e, em menor número, lojas de artesanato e locais de exposições. Embora o escritório local sugerido pela Fundação Roberto Marinho tenha indicado diversas atividades econômicas para a área, a fim de imprimir-lhe um maior dinamismo, o mercado foi o verdadeiro guia dos investimentos. Como reconhece o técnico do Departamento de Patrimônio da Secretaria de Cultura e Desporto do Estado do Ceará, "de dia [é] aquela coisa meio morta porque não tem atividade diurna. O que tem de diurno é muito incipiente" (Frederico Bastos, entrevistas em janeiro de 2002).

A definição do trabalho de revitalização do entorno do Dragão do Mar usou como justificativa a importância histórica da área, detentora de edificaçōes de interesse para preservação. Entretanto, nenhuma das edificações era tombada quando da intervenção. Por outro lado, o Conselho Estadual de Preservação do Patrimônio Cultural do Estado do Ceará encontrava-se desativado à época dos trabalhos de intervenção, aguardando a definição de sua nova estrutura. Para conseguir assegurar a preservação das edificaçōes da área, os técnicos relatam um árduo processo de convencimento dos proprietários.

A percepção dos riscos que o sucesso da revitalização coloca para a sua continuidade faz com que haja uma defesa do tombamento dos imóveis da área. Entretanto, o tombamento das cerca de 50 edificaçôes atingidas pelo projeto de revitalização representaria uma redefinição completa do perfil dos bens imóveis tombados na cidade de Fortaleza. Até o ano de 2001, eram 18 imóveis tombados, sendo 6 de proteção federal, através do IPHAN, e 12 de proteção estadual, através do Conselho Estadual de
Preservação do Patrimônio Cultural do Estado do Ceará. Todos os bens tombados são edificaçôes isoladas, marcadas sobretudo pela singularidade, ainda mais reforçada pela monumentalidade dada pelo tombamento. A inserção dos imóveis que integram a área do Centro Dragão do Mar de Arte e Cultura implicaria em quadruplicar o total de bens protegidos pelo instituto do tombamento. Além disso, significaria a inclusão de imóveis marcados não pelo que têm de singular e atípico, mas pelo que significam em termos da definição da ambiência de um determinado espaço da cidade.

\subsection{A área revitalizada: situação atual}

Quem se dirige à área do Centro Dragão do Mar de Arte e Cultura durante a manhã e ao princípio da tarde encontra sua praça central absolutamente calma. Praticamente todos os estabelecimentos comerciais permanecem fechados. Apenas por volta das 16 horas os primeiros bares começam a abrir. Tal quietude contrasta vivamente com o movimento da Avenida Almirante Barroso que a limita ao norte. Nessa Avenida, localizam-se diversas repartiçōes públicas (em edificações consideradas de valor histórico) e estabelecimentos comerciais (em edificações contemporâneas). Ela também marca a divisa entre a área revitalizada e os quarteiróes que vão dar no mar. Nesses quarteirōes, localizam-se desde edifícios de apartamento de construção recente até quadras de ocupação espontânea qualificadas como favela na fala dos moradores e dos agentes do poder público. Seguindo em direção oeste, a Avenida Castelo Branco faz a ligação com outro equipamento urbano de grande porte e de interesse turístico: o Mercado Central. Entretanto, essa via apresenta-se bastante degrada$\mathrm{da}$, com pouco movimento de pedestres por suas calçadas estreitas e semi-destruídas. Algumas moradias precárias e edificaçôes com vãos fechados em alvenaria completam o quadro de abandono.

A leste do Dragão do Mar, a Avenida Castelo Branco dá lugar à Avenida Monsenhor Tabosa, importante eixo voltado sobretudo para a comercialização de artigos têxteis e artesanato. Considerado elemento integrante dos roteiros turísticos, essa via se estende por diversos quarteirōes até se encontrar com a área de hotéis e restaurantes da Praia de Iracema. Inicia-se, a partir daí, a área mais nobre da cidade. Embora a Avenida Monsenhor Tabosa 
seja marcada por um comércio bem qualificado, voltado para turistas e para a classe média local, os quarteirōes lindeiros que se dirigem para o mar apresentam uma ocupação rarefeita, com muitas edificações degradadas.

O Centro Dragão do Mar de Arte e Cultura, portanto, é um nódulo incrustado na ponta do eixo de frequência dos turistas e da classe média local. A intenção inicial de sua construção era exatamente essa: configurar-se como uma ponta que estimularia o processo de renovação do seu entorno. Desde a sua inauguração, ele tem cumprido parcialmente esse papel. Nos quarteiróes situados a leste da área de intervenção (portanto abaixo da Avenida Monsenhor Tabosa), ainda predominam as edificaçôes com os usos tradicionais da área (armazéns, depósitos, estacionamentos, algumas moradias degradadas ao lado de outras em bom estado de conservação). Como disse, é uma ocupação rarefeita, inclusive com alguns quintais amplos, dando à área uma ambiência interiorana. Ao fundo, essa paisagem é interrompida pela torre de um flat, que assume uma aparência deslocada.

Ao mesmo tempo, começa a haver a ocupação de alguns imóveis com atividades características da área revitalizada; eles assumem, todavia, um perfil mais "alternativo". Nos quarteirões a oeste da área de intervenção (portanto abaixo da Avenida Castelo Branco), o cenário se repete: usos tradicionais convivendo com os primeiros transbordamentos de atividades da área revitalizada. Nessa porção oeste, contudo, a ocupação é mais adensada.

À medida que a noite se aproxima, a área muda sua configuração. Aos poucos, os bares, restaurantes e lojas vão se abrindo. Freqüentadores da praça formada à frente do Centro Dragão do Mar de Arte e Cultura começam a ocupar os bancos disponíveis. $\mathrm{Na}$ quadra poliesportiva, iniciam-se os primeiros jogos. Essa freqüência aumenta gradativamente, percebendo-se a chegada de famílias, algumas delas com a clara aparência de turistas. A ocupação inicial das mesas dos bares e restaurantes é, sobretudo, por essas famílias ou por grupos de amigos saindo do trabalho. A partir das 24 horas, tal freqüência se esvai e, sobretudo a partir das quintas-feiras, é substituída pelos jovens que se dirigem às boates. Com eles, instalam-se as barracas de camelôs vendendo bebidas e os carros vendendo alimentos (sanduíches, pizzas e outros). Esse público transborda o entorno do Centro Dragão do Mar de Arte e Cultura e penetra nas ruas adjacentes, onde se localizam outras boates e bares. Alguns deles já existiam antes da revitalização, enquanto as demais surgiram mais recentemente. Na praça central, grupos de jovens punks, heavy metal ou de aparência mais convencional reúnem-se em grupos guardando distância respeitosa entre si. Esse será o movimento da área até o fechamento das boates e a saída dos últimos freqüentadores.

A experiência de Fortaleza apresenta-se como um contraponto à de Vitória. Em primeiro lugar, o poder público estadual é o condutor único da revitalização. Há uma absoluta ausência do poder público municipal, inclusive no que diz respeito a diversas de suas tarefas precípuas (como a fiscalização dos usos da área, por exemplo). Em segundo lugar, a revitalização foi bastante concentrada, atingindo um conjunto restrito de quarteirôes que formavam a moldura do grande equipamento cultural ali instalado. Esse equipamento cultural é o condutor das atividades da área através das programações que desenvolve em seu interior ou nos espaços externos adjacentes. Nesse sentido, ele tem se comportado como os museus e outros centros de mesma natureza que têm se pautado por uma certa lógica mercadológica para atrair o grande público ${ }^{19}$. Em terceiro lugar, a área não apresentava um conjunto histórico reconhecido e monumentalizado pelo tombamento. A transformação dos edifícios da área em patrimônio histórico (ainda que não tombado) ocorreu como um desdobramento da implantação do Centro Dragão do Mar de Arte e Cultura.

Porém, o que mais contrasta com Vitória é a dinâmica do uso. Embora ambas as áreas (mas sobretudo Fortaleza) careçam de habitantes na área revitalizada, o efeito sobre a dinâmica do seu uso cotidiano é o oposto. A ênfase comercial do centro de Vitória implica em uso diurno e esvaziamento noturno, enquanto o foco turístico e de diversóes dado à área de Fortaleza implica em uso noturno e esvaziamento diurno. Quanto a traços de

19 Sobre algumas experiências recentes, ver van Aalst e Boogaarts (2002) e Plaza (2000), dentre outros. 
gentrification, eles são significativos em Fortaleza. Os antigos (e raros) habitantes foram deslocados (ainda que para a vizinhança, como vim a perceber) e os usos foram totalmente redefinidos; mas, só podemos falar em uma gentrification de consumo e de frequência (ver Bidou-Zachariasen, 2003).

\section{O Caso de São Luís}

\subsection{Evolução urbana}

A cidade de São Luís contava com 870 mil habitantes em 2000. Ela centraliza uma região metropolitana com 1,07 milhão de moradores, segundo o mesmo censo. Destaca-se por concentrar as atividades industriais e portuárias do Estado, em função do complexo portuário de Itaqui. Também é uma importante área de atração turística.

A cidade foi fundada por franceses em $1612 \mathrm{e}$ tomada pelos portugueses em 1614. Como toda a porção norte da América portuguesa, a região permaneceu sob a ameaça de invasões de outros estados europeus até princípios do século XVIII. Sua economia baseava-se no cultivo do algodão e do arroz e na produção pecuária, além de exportar produtos coletados na flora nativa. A produção de algodão deu ensejo ao surgimento de algumas fábricas têxteis, que entretanto não transcenderam os mercados locais. No século XIX e na primeira metade do século XX, a presença da burocracia estadual e de atividades portuárias modestas garantiu a presença da elite local no centro urbano de São Luís.

Ao longo do século XX, a cidade expandiu-se para além desse centro histórico, incorporando novos bairros à sua configuração urbana. A saída das classes alta e médias para os novos bairros que se formavam fez com que a região fosse progressivamente ocupada por segmentos mais pobres da população. A partir da década de 1970, as construçōes da barragem sobre o rio Bacanga e da ponte sobre o rio Anil permitiram a abertura de novas áreas para o crescimento da cidade. Nas novas regiōes, foram implantados empreendimentos voltados para as classes alta e médias da cidade, fazendo com que o centro histórico fosse se tornando uma área à qual esses segmentos da população se dirigiam apenas em caráter excepcional (Corrêa, 2001). Houve uma degradação ainda maior de alguns imóveis abando- nados enquanto outros foram transformados em habitações coletivas de condiçōes precárias.

A permanência de atividades comerciais e administrativas no interior ou no entorno do centro histórico evitou que ele se transformasse em uma zona degradada e sem importância no contexto urbano (Corrêa, 2001). Aliado a isso, o tombamento federal, que ocorreu na década de 1950, e o estadual, na década de 1980, garantiram a preservação do seu conjunto arquitetônico. Segundo Corrêa (2001), o Centro Histórico possui um conjunto marcante e compacto de casarios e construçōes coloniais, porém, sem grandes monumentos; o que se destaca é uma arquitetura civil de valor inestimável.

\subsection{Patrimônio histórico e revitalização urbana}

O centro histórico de São Luís foi tombado pelo IPHAN em dois momentos: em 23 de dezembro de 1953 e em 13 de março de 1974. Definiu-se uma área de cerca de 90 hectares onde existem mais de mil edificações consideradas de valor histórico e paisagístico, compreendendo os bairros da Praia Grande, Desterro e Ribeirão, além de algumas praças. Posteriormente, em 6 de março de 1986, o decreto estadual no. 10.089 tornou protegida uma área ainda maior, com cerca de 160 hectares e aproximadamente 2.500 imóveis. Finalmente, através do Plano Diretor Urbanístico de 1992 (Lei Municipal no. 2.352, de 29 de dezembro de 1992), o centro foi dividido em duas grandes zonas de proteção: $\mathrm{Z} \mathrm{ZPH}$ (Zona de Proteção Histórica), que abrange as duas áreas protegidas pelos tombamentos federal e estadual; e a ZPH2, que corresponde às áreas de entorno e preservação ambiental do Aterro do Bacanga e do Parque do Bom Menino ${ }^{20}$.

Em finais da década de 1970, em função de alguns programas governamentais (sobretudo o Programa Integrado de Reconstrução das Cidades Históricas do Nordeste, da Secretaria de Planejamento da Presidência da República), foram se estruturando algumas intervenções visando a restauração de alguns imóveis mais expressivos. Em 1980, após mobilizações no seio do próprio governo estadual, foi criado um grupo de trabalho do Projeto Praia

${ }^{20}$ Estas informaçōes e outras colocadas adiante foram extraídas da página sobre São Luís no site do Governo do Estado do Maranhão, http://www.ma.gov.br/sao_luis. 
Grande, que elaborou o primeiro projeto de intervenção maciça. Privilegiou-se a zona da Praia Grande, sobretudo a Praça do Comércio, a Feira Grande e vizinhanças. Após uma interrupção de quase cinco anos, os trabalhos foram retomados em 1987, com a ascensão do ex-governador José Sarney à presidência da República. Foram realizadas obras de infra-estrutura (renovação de redes de água, de luz e de telefone, renovação da pavimentação das ruas, reconstrução de escadarias e outros) e $10 \mathrm{mil}$ metros quadrados de prédios foram restaurados, além de se instalarem outros equipamentos culturais (Centro de Criatividade Odylo Costa, filho; Fundação da Memória Republicana, no Convento das Mercês; Centro de Comercialização de Produtos Artesanais do Maranhão, no bairro Madre Deus).

Nos anos seguintes, novas intervenções pontuais foram realizadas, como a restauração de imóveis, a reforma do Teatro Arthur Azevedo e outras. Além disso, em 1990 foi realizado o Projeto Piloto de Habitação, que consistiu na restauração de um sobrado no Centro Histórico e sua adaptação para a moradia de 10 famílias. A partir de meados da década de 1990, os projetos de preservação passaram a contar com financiamentos ainda maiores, como foi o caso do PRODETUR (Programa de Ação para o Desenvolvimento Turístico do Nordeste), que permitiu o aporte de recursos do Banco Interamericano de Desenvolvimento (BID), do Governo Federal e do Governo Estadual da ordem de 10 milhões de dólares. Em 1997, a cidade foi inscrita pela UNESCO na lista dos Monumentos Culturais da Humanidade ${ }^{21}$.

Como se percebe do relato acima, os investimentos no processo de revitalização do centro histórico de São Luís foram capitaneados, sobretudo, pelo governo estadual. A decisão de criar uma equipe técnica (mantida quase integralmente desde o final da década de 1970 até os dias atuais), de fazer inversōes próprias e de buscar recursos em outras instâncias governamentais e internacionais foi tomada e levada adiante pelos órgãos estaduais envolvidos com a questão. Pela documentação produzida ao longo de todo o período, percebe-se um empenho pessoal de alguns governadores, que tomaram as obras

\footnotetext{
${ }^{21}$ Sobre a proposta de elevação a patrimônio da humanidade, ver Governo do Estado do Maranhão (1997).
}

de revitalização como aspecto central dos seus governos $^{22}$.

O governo municipal apenas recentemente passou a se envolver mais diretamente com os rumos do processo de revitalização. Em 1992, o Plano Diretor Urbanístico consagrou a proteção às áreas tombadas e seus entornos dentro da legislação municipal. A partir de 1998, a Fundação Municipal de Cultura passou a agir de forma mais visível, estando atualmente empenhada em tornar efetivo o Conselho Municipal de Cultura e suas atribuiçóes quanto à preservação do patrimônio de caráter local. Além disso, a Prefeitura Municipal tem atuado junto às populações residentes no centro histórico, procurando conhece-la melhor e construir alternativas de moradia para que a continuidade do processo de revitalização não redunde em exclusão daqueles que habitavam o lugar ${ }^{23}$.

\subsection{A área revitalizada: situação atual}

Quem anda pela área do Projeto Reviver constata uma atividade febril durante o dia. O movimento em torno dos órgãos públicos (a Câmara dos Vereadores, a Faculdade de Arquitetura da universidade estadual, as repartiçôes públicas estaduais ali instaladas) e das atividades comerciais de feitio tradicional que ainda existem por lá (sobretudo o Mercado) enchem de vida a região. Nas quadras adjacentes, ainda encontram-se instalados órgãos da administração superior dos poderes públicos estaduais, além da existência de um comércio popular vigoroso. Alguns equipamentos voltados para o turismo completam o leque das atraçóes ali encontradas.

À noite, o movimento segue em ritmo marcado pelos dias da semana. A segunda-feira e a terça-feira são dias vazios. Apenas na quarta-feira há uma movimentação um pouco mais intensa. A partir da quinta-feira, inicia-se um crescendo que culmina no sábado. No período das férias (dezembro/janeiro/ fevereiro e julho), o sábado sempre é marcado por

${ }^{22}$ A este respeito, ver Gisiger (s/d); Comissão de Coordenação do Projeto Praia Grande (1981); Pereira (1993); e Governo do Estado do Maranhão (1993).

${ }^{23}$ Sobre o envolvimento do poder público local, ver Corrêa (2001). 
algum evento festivo. Os donos de bares e restaurantes que se instalaram ali para se aproveitarem das vantagens oferecidas pela revitalização são unânimes em constatar que o público freqüentador da área é constituído sobretudo de turistas. Os habitantes da cidade que poderiam completar o público consumidor continuam afastados, para além do rio Anil. Há uma resistência surda a repensar o lugar do centro no imaginário e na vivência da cidade por esta parcela de sua população, apesar dos processos de intervenção já durarem quase três décadas.

A população empobrecida, por sua vez, que ocupou as edificaçōes históricas na medida em que foram sendo abandonadas pelas classes médias, hoje se sente ameaçada pelo avanço da revitalização sobre as quadras adjacentes ao núcleo inicial da Praia Grande. Muitos imóveis foram desocupados, com os moradores deslocados para conjuntos habitacionais situados em regiōes periféricas, distantes de suas fontes de renda (sobretudo o comércio informal e os pequenos serviços) e de suas redes de relaçôes sociais. Em janeiro de 2003, diversas edificaçōes estavam em vias de serem desocupadas para receber projetos de restauração e readequação de uso, e os habitantes seriam novamente deslocados para conjuntos habitacionais na periferia. Para reagir a estes problemas, foi criada a União dos Moradores do Centro Histórico de São Luís, que tem tentado servir como um canal de comunicação entre os moradores ameaçados de despejo e os órgãos públicos. Segundo o depoimento de diretores da União, embora tenham conseguido estabelecer contatos profícuos com a Prefeitura Municipal, os órgãos estaduais permanecem refratários a negociaçōes ${ }^{24}$.

O caso de São Luís apresenta algumas características interessantes que merecem reflexão tanto em face das outras experiências aqui relatadas quanto em relação a outros processos de revitalização. $\mathrm{O}$ primeiro aspecto diz respeito à preeminência do governo estadual na gestão e implantação de todos os projetos de revitalização. Desde cedo, esta se tornou uma tarefa capitaneada pelo poder público estadual, com o governo federal (através do IPHAN) e o municipal vindo a reboque. Também chama a

${ }^{24}$ Wellington Melo Pereira e Sandra Maria Fernandes, Uniāo dos Moradores do Centro Histórico de São Luís, entrevista em 21/01/2003. atenção a longevidade da experiência. São cerca de três décadas de trabalho e de investimentos continuados na recuperação do centro histórico de São Luís. Isso é justificado pelo alto valor simbólico de que a área foi investida desde o tombamento pioneiro da década de 1950, reforçado pela Unesco com a declaração de patrimônio da humanidade em 1997.

Por outro lado, a longevidade e o vulto dos investimentos não significou uma modificação da postura da população da cidade em relação ao centro histórico. Ele permanece como uma área para turistas, com os habitantes da cidade se mantendo distantes e só se aproximando em ocasiōes especiais ou quando são transformados em cicerones de amigos em visita à cidade. Em conseqüência, não se pode pensar em processos de gentrification plena, já que os investimentos na área não se reverteram em ganhos para o capital imobiliário nem atraíram novos moradores endinheirados. Como em Fortaleza, pode-se reconhecer uma gentrification de freqüência e de consumo, nos termos de Bidou-Zachariasen (2003). O processo de exclusão dos que habitavam o centro degradado tem se dado através de uma política estatal de remoção para áreas periféricas. $\mathrm{O}$ vazio criado tem servido para instalar órgãos da burocracia estatal ou para criar moradias para novos habitantes, sobretudo funcionários públicos estaduais dos baixos estratos burocráticos.

Pode-se dizer, em conclusão, que o futuro desta experiência de revitalização depende da disposição dos poderes públicos em continuar a investir na área, bem como na dinâmica entre os rumos destes investimentos e os embates com os segmentos da população atingidos por eles. Em outras palavras, a reação dos que moram na área e se sentem ameaçados de expulsão quanto dos que não são dali e se recusam a reincorporar o centro ao seu universo de vivência da cidade darão o tom dos desdobramentos da experiência de revitalização do centro histórico de São Luís.

\section{Conclusão}

A partir da pesquisa, foi possível observar como tais locais são alvos de altos investimentos governamentais durante anos contínuos, sempre justificados pelos desafios que a globalização colocaria para as suas cidades. Os discursos dos gestores públi- 
cos e dos patrocinadores associam a necessidade de recuperação das áreas centrais degradadas como parte do processo de "recolocação" de suas cidades no cenário globalizado. As práticas adotadas a partir destes discursos tendem a assumir uma postura elitizante, procurando excluir segmentos considerados indesejáveis. Ou, em outro registro, assumem que a revitalização destina-se a atrair determinados moradores/consumidores, em contraposição ao que existiria no lugar antes de iniciado o processo.

Ao lado destes aspectos elitizantes, próximos ao que em outros locais pode ser denominado de gentrification, o que se observa nas áreas brasileiras aqui estudadas é uma interessante reapropriação do espaço urbano por parte do segmento que sempre usufruiu daquele lugar. Assim, quando estas áreas alcançam sucesso na sua reconfiguração (como em Fortaleza), torna-se um interessante local de trabalho para vendedores ambulantes, ou atrai tribos urbanas inusitadas e pouco esperadas por aqueles que pensaram o espaço. Em outros locais, o sucesso da revitalização ocorre em ambientes políticos excludentes, e embora não encontrem oposição eficaz, fazem surgir movimentos de apoio aos moradores em processo de expulsão; é o caso de São Luís. Pode ocorrer, entretanto, um processo ambíguo, em que ao discurso da globalização e da reestruturação urbana associa-se o do atendimento de demandas locais, e os processos de revitalização estão sempre recorrendo ao diálogo direto com a população local, em uma tentativa de inventar tradiçôes e reafirmar a antiga centralidade. Isto é o que se observa em Vitória.

De todo modo, é interessante observar que os casos de revitalização em análise apresentam uma singular articulação entre o discurso da globalização (apoiado, sobretudo, no apelo turístico), com uma prática usualmente excludente, e uma vigorosa resistência a estes processos, com apropriaçôes bastante inovadoras das áreas revitalizadas por parte dos moradores destas cidades.

\section{Referências bibliográficas}

Aalst, I. van e I. Boogaarts (2002). “From museum to mass entertainment: the evolution of the role of museums in cities". European Urban and Regional Studies, 9, 3: 195-209.
Acselrad, H. (2001). "Sentidos da sustentabilidade urbana”. Acselrad. H. (ed.), A duração das cidades: sustentabilidade e risco nas politicas urbanas. Rio de Janeiro: DP\&A/Crea-RJ, 27-55.

Arantes, A.A. (ed.) (2000). O espaço da diferença. Campinas: Papirus.

Azevedo, R.M. de (1994). "Será o novo Pelourinho um engano?” Revista do Patrimônio Histórico e Artístico Nacional, 23: 131-7.

Bank, G. (1998). "A cidade que desejamos depois do ano 2000: participação política e construção do imaginário urbano em Vitória”. Bank, G. (ed), Dilemas e símbolos: estudos sobre a cultura politica do Espirito Santo. Vitória: Instituto Histórico e Geográfico do Espírito Santo, 229-260.

Banco Interamericano de Desarrollo (BID) (1998). La ciudad en el siglo XXI: experiencias exitosas en gestión del desarrollo urbano en América Latina. Washington, D.C.: BID.

Barreira, I. (2001a). "Langage de la ville et patrimoine: lê dialogue entre passe et présent". Martin, J.-B. (ed.), Usages sociaux de la memoire et de l'imaginaire au Brésil et en France. Lyon: Presses Universitaires de Lyon, 271-292.

(2001b). "Preservar a cidade: o centro como patrimônio cultural”. Aguiar, O.A., J.E. Batista e J. Pinheiro (eds.), Olhares contemporâneos: cenas do mundo em discussão na universidade. Fortaleza: Fundação Demócrito Rocha, 29-39.

(2003). "A cidade no fluxo do tempo: invenção do passado e patrimônio". Sociologias, 5, 9: 314-339.

Benevides, I.P. (1998). Turismo e Prodetur. dimensōes e olhares em parceria. Fortaleza: Editora da UFC.

Benevides, I.P. e L. Gondim (1998). “Prostiturismo' feminino em Fortaleza: um encontro de Cupido com Mercúrio?" Benevides, I.P. (ed.), Turismo e Prodetur: dimensóes e olhares em parceria. Fortaleza: Editora da UFC, 137-151.

Bidou-Zachariasen, C. (2003). "Introduction". Bidou-Zachariasen, C. (ed.). Retours en ville: des processus de 'gentrification' urbaine aux politiques de 'revitalization' des centres. Paris: Descartes \& Cie., 9-42.

Botechia, F.R. (2001). Áreas centrais em transformação: os tempos e os espaços no centro tradicional de Vitória (ES). Belo Horizonte: UFMG. Bright, E.M. (2000). Reviving America's forgotten 
neighborhoods. New York-London: Routledge.

Campos Jr., C.T. de (2002). A construção da cidade: formas de produção imobiliária em Vitória. Vitória: Florecultura.

Comissão de Coordenação do Projeto Praia Grande (1981). Projeto Praia Grande: programa de obras para o Largo do Comércio e adjacências. São Luís: Governo do Estado do Maranhão.

Corrêa, A.F. (2001). Vilas, parques, bairros e terreiros: novos patrimônios na cena das politicas culturais em São Paulo e São Luís. São Paulo: PUC-SP.

Fonseca, I.C. da (2003).Comentário sobre o Projeto de Revitalização do Centro de Vitória. Belo Horizonte: PUCMinas.

Frúgoli, H. (2000). Centralidade em São Paulo: trajetórias, conflitos e negociaçôes na metrópole. São Paulo: Cortez/EDUSP.

Gisiger, J.U. (s/d). Renovação urbana da Praia Grande, São Luís/Maranhão. São Luís: Governo do Estado do Maranhão,.

Gomes, M.A.A. de F. (ed.) (1995). Pelo Pelô: história, cultura e cidade. Salvador: Editora da Universidade Federal da Bahia.

Gondim, L. (2001a). "Dessin urbaine et imaginaire social: le role du Centre Dragão do Mar d'art et culture dana la production de l'image de Fortaleza (Brésil)". Martin, J.-B. (ed.), Usages sociaux de la memoire et de l'imaginaire au Brésil et en France. Lyon: Presses Universitaires de Lyon, 157-174.

(2001b). "A construção social da memória na moderna Fortaleza". Aguiar, O.A., J.E. Batista e J. Pinheiro (ed.), Olhares contemporâneos: cenas do mundo em discussão na universidade. Fortaleza: Fundação Demócrito Rocha, 174-189.

(2003). "Representações sobre cultura e patrimônio na produção imaginária da cidade global: panorama visto da periferia”. Paper apresentado ao XXVII Encontro Anual da ANPOCS, Caxambu.

Governo do Estado do Maranhão (1993). Projeto de promoção social e habitação no Centro Histórico de São Luís. São Luís: Governo do Estado do Maranhão, Secretaria do Estado da Cultura. (1997). Proposta

do Governo do Estado do Maranhão para inclusão do Centro Histórico de São Luís na lista do Patrimônio Mundial da Unesco. São Luís: Governo do Estado do Maranhão.

Hiernaux-Nicolás, D. (2003). "La réappropration de quartiers de México par les classes moyennes: vers une gentrification?" Bidou-Zachariasen, $\mathrm{C}$. (ed.), Retours en ville: des processus de 'gentrification' urbaine aux politiques de 'revitalization' des centres. Paris: Descartes \& Cie., 205-240.

Huyssen, A. (2000). Seduzidos pela memória: arquitetura, monumento, mídia. Rio de Janeiro: Aeroplano.

Jacobs, J. (2001). Morte e vida de grandes cidades. São Paulo: Martins Fontes.

Leite, R. P. (2002). “Contra-usos e espaço público: notas sobre a construção social dos lugares na Maguetown”. Revista Brasileira de Ciências Sociais, 17, 49: 115-134.

(2003). "Localizando o espaço público: lugares, política e desentendimento". Paper apresentado ao XXVII Encontro Anual da ANPOCS, Caxambu.

Melè, P. (1998). Patrimoine et action publique au centre des villes mexicaines. Paris: Presses de la Sorbonne Nouvelle/Editions de l'IHEAL.

Plaza, B. (2000). "Evaluating the influence of a large cultural artifact in the attraction of tourism: the Guggenheim Museum Bilbao case". Urban Affairs Review, 36, 2: 264-274.

Pereira, E.C.A. (1993). Reviver. Brasília: Senado Federal.

Prefeitura Municipal de Vitória (s/d). Programa de Revalorização do Centro, Vitória-ES: Documento Monumenta BID. Vitória: Prefeitura Municipal de Vitória.

(1996). Vitória do Futuro. Vitória: Prefeitura Municipal de Vitória.

Sánchez, F. (2001). "A reinvenção das cidades na virada do século: agentes, estratégias e escalas de ação política”. Revista de Sociologia e Politica, 16: 31-49.

Smith, N. (1996). The new urban frontier: gentrification and the revanchist city. New YorkLondon: Routledge.

Smith, N. (2003). "La gentrification généralisée: d'une anomalie locale à la 'régénération urbaine 
comme estratégie urbaine globale". BidouZachariasen, C. (ed.). Retours en ville: desprocessus de 'gentrification' urbaine aux politiques de 'revitalization' des centres. Paris: Descartes \& Cie., 45-72.

Souza, S. de (ed.) (1989). História do Ceará. Fortaleza: Universidade Federal do Ceará/Stylus Comunicações.

Vainer, C. (2000a). "Pátria, empresa e mercadoria: notas sobre a estratégia discursiva do Planejamento Estratégico Urbano". Arantes, O., C. Vainer e E. Maricato (eds.), A cidade do pensamento unico. Petrópolis: Vozes, 75-103.

(2000b). "Os liberais também fazem planejamento estratégico? Glosas ao 'Plano Estratégico da Cidade do Rio de Janeiro'”. Arantes,
O., C. Vainer e E. Maricato (eds.), A cidade do pensamento único. Petrópolis: Vozes, 105-119. Zanchetti, S.M. e N. Lacerda (1999). "A revitalização de áreas históricas como estratégia de desenvolvimento local: avaliação do caso do Bairro do Recife". Revista Econômica do Nordeste, 30, 1: 8-24.

Zukin, S. (1991). Landscapes of power: From Detroit to Disneyworld. Berkeley-Los Angeles: University of California Press. (1995). The cultures of cities. CambridgeOxford: Blackwell Publishers.

(2000). "Paisagens urbanas pós-modernas: mapeando cultura e poder”. Arantes, A.A. (ed.), O espaço da diferença. Campinas-SP: Papirus, 80-103. 